\title{
Simulation of Different SPI Models
}

\author{
Bharti Sharma \\ Student, M-tech \\ Department of CSE \\ Punjabi University Patiala
}

\author{
Neeraj Sharma \\ Lecturer \\ Department of CSE \\ Punjabi University \\ Patiala
}

\author{
Neeshu Sharma \\ Student, M-tech \\ Department of CSE \\ PTU, Jallandhar
}

\begin{abstract}
:
Software process improvement is recognized as an important part of the software development life cycle. Several contemporary models have been developed to assist organizations evaluate and improve their software development processes and capabilities. This study provide simulation of the existing models ( Capability Maturity Model, ISO, SPIQ, ProPAM, Bootstrap, Trillium, SixSigma, SPICE ), analyze each models along with their importance and drawbacks .
\end{abstract}

\section{INTRODUCTION}

The term "software process improvement" denotes the "changes implemented to a software process that bring about improvements". Numerous software process improvement (SPI) method in market offer help and guidance, but unfortunately they only partially address factors found essential for achieving SPI success. Steps for SPI are given below :

1. Examine current techniques and apparent strengths and weaknesses;

2. Provide guidance for assessing emerging techniques; and

3. Report findings that are useful to acquirers and developers and the other SPI focus groups.

\section{BACKGROUND :}

The purpose of this research work is to give a very brief introduction to some of the most commonly recognized SPI models ,SPICE, SWCMM, CMMI, ISO 9001:2000,SPIQ Trillium, BOOTSTRAP and Six Sigma, to readers who are not familiar with SPI.

\section{CMM}

Its goal is to improve, over time, the application of an organization's software technologies. The CMM process is made up of five welldefined levels of sequential development: initial, repeatable, defined, managed, and optimizing [7]. However, there were hints that small companies found pieces of the CMM irrelevant and hard to apply[6]. Problems typically reported with the CCM when used by these organizations were: Documentation overload, Unrelated management structure, High resource requirements, High training costs, Lack of need guidance, Unrelated practices

\section{ISO9000:2000,9001:2000,9004:2000}

ISO 9001 is an international standard for quality assurance in design, development, production, installation, and service [6].
Other benefits included higher product quality, greater internal quality awareness, and increased competitive advantage. ISO 9001 is similar to the CMM in the following areas: emphasis on process, documented processes, practiced processes, address the "what" and not the "how" [7] The major problem with ISO 9000, it involves too much bureaucracy, and some organization just need ISO 9000 certification for marketing purpose as against software process improvement that is the main objective. Also too much documentation is required, lot of resources (time, cost and effort) to implement ISO 9000.

\section{BOOTSTRAP :}

BOOTSTRAP is a European method for software process assessment and improvement that was developed to speed up the application of software engineering technology in the European software industry [7].The main features of BOOTSTRAP are: Questionnaires for both site and project evaluation, Uniform procedure and mandatory assessor qualification/training, Constructive instead of a normative approach, Open questions, Immediate feedback and action planning.

\section{SPIQ :}

SPIQ or Software Process Improvement for better Quality. They operate in different do-mains, apply different development technologies, and represent different sizes (teams of 2-10 persons) and company cultures. SPIQ is planned with three main phases over 5.5 years: Phase 1 (1.5 years): Getting started and running the first SPI experiments. An initial SPI method book for Norwegian SMEs and a demonstrator experience database will be provided. Phase 2 (two years): Refining the experiments on similar processes. A complete method book, experience database, and high-level PML will be provided. Phase 3 (two years): Consolidating the experiments on other kinds of processes.

\section{ProPAM :}

In ProPAM, a process is defined as an instance of PIT-Process metamodel [4]. A process is defined by a set of phases which are composed by several iterations. Disciplines and activities, work products and roles define the space of possible choices for projects within a given process. Activities can be defined according activity/sub- activities relationships represented in a hierarchical work breakdown. 


\section{SPICE :}

SPICE stands for Software Process Improvement and Capability Determination. The objective of an assessment on the other hand is to; decide if the performance of the process/processes is satisfying and if the processes are effective in achieving their goals, and to distinguish and determine the capability of the process. The result of the assessment is analyzed to determine the weaknesses, strengths and risks of the process. This can be used as a base for process improvement.

Six Sigma :

" $\sigma$ " (sigma) is a Greek letter that stands for standards deviation - a measure of dispersion, variation or spread. Six Sigma is a methodology for eliminating defects, waste, or quality control problems that originated at Motorola in the early 1980's. Key features of the methodology are; statistical quality control techniques, data analysis methods, and systematic training of people in the organization that is affected or targeted by Six Sigma. Six Sigma is a data driven methodology that addresses a variety of business activities such as manufacturing and management.

The method Six Sigma is defined as a business improvement strategy used to improve business profitability, to drive out waste, to reduce costs of poor quality and to improve the effectiveness and efficiency of all operations so as to meet or even exceed customers' needs and expectations. The name Six Sigma comes from the statistical term 3.4 defects per million opportunities (DPMO), where sigma is a term used to represent the variation about the average of a process by Coronado et al[2]. In short the objectives of Six Sigma are the implementation of a measurement-based strategy that is focused on process improvement and variation reduction. Waste and cost is removed from the organization and customer satisfaction is increased through continuous quality improvement.

\section{Trillium :}

The goal with the Trillium model is to help organizations to start and conduct a process improvement program that is continuous. The model provides key industry practices, which can be used to improve existing processes or life cycles.

The Trillium model is based on the Carnegie Mellon University Software Engineering Institute's (SEI) Capability Maturity Model (CMM) v1.1 initially developed by W. Humphrey and collaborators for the United States Department of Defence. To fully understand the Trillium model, it is desirable to have a background in product engineering and quality management, and a solid understanding of the source documents listed above. The Trillium model has :

- A telecommunications orientation.

- Provides a customer focus.

- $\quad$ Provides a product perspective.
- Covers ISO, Bellcore, Malcolm Baldrige, IEEE and IEC standards.

- Includes technological maturity.

- Includes additional Trillium-specific practices.

- Provides a roadmap approach, which sequences improvements by maturity.

\section{ANALYSIS OF SPI MODEL:}

Analysis of each models shown in Table:1.

\section{CONCLUSIONS}

In this paper, we have discussed the ISO CMMI, and the new ProPAM approach. We showed that approaches, like ISO and CMMI, are not specific enough to catch the needs of certain type of organizations, its business needs and its business goals. The prescriptive nature of ISO and CMMI, and the associated investment necessary to implement SPI programs are the main reasons for further researches on SPI approaches based on experience, such as ProPAM.

\section{REFERENCES}

1. Brodman, J., \& Johnson, D. (1997). A software process improvement approach for small organizations and small projects. Paper presented at the International Conference on Software Engineering, Boston, MA.

2. Coronado and Antony, 2002, "Critical success factors for the successful implementation of six sigma projects in organizations". The TQM Magazine. v14 i2. 92-99.

3. Herbsleb, J., Zubrow, D., Goldenson, D., Hayes, W., \& Paulk, M. (1997). Software quality and the capability maturity model. Communications of the ACM, 40(6), 30-40.

4. Paula Ventura Martins, Alberto Rodrigues da Silva " $A$ camapartive study of SPI approaches in proPAM model" QUATIC '07: Proceedings of the 6th International Conference on Quality of Information and Communications Technology, September 2007

5. Weissfelner, S. (1999). ISO 9001 for Software Organizations. "Elements of Software Process Assessment and Improvement Washington".

6. Wiegers, K. (1999). "Software process improvement in Web time". IEEE Software, 16(4), 78-76.

7. Zahran. (1998). "Software Process Improvement: Practical Guidelines for Business Success. Reading, MA:Addison 


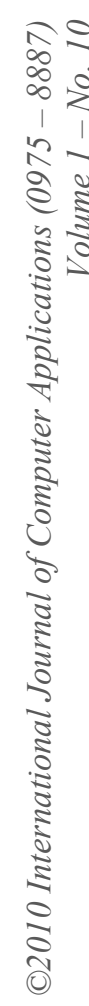

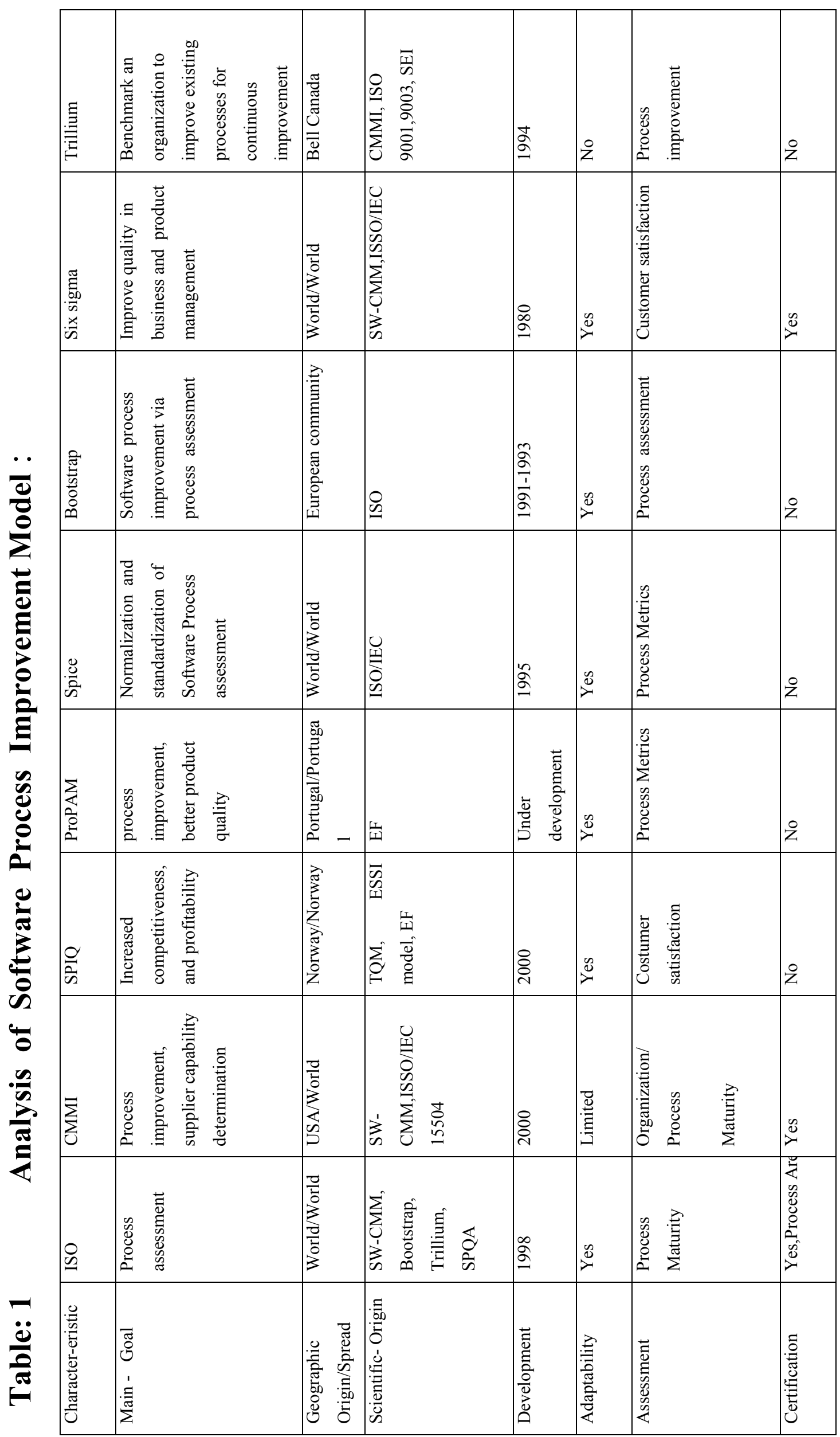




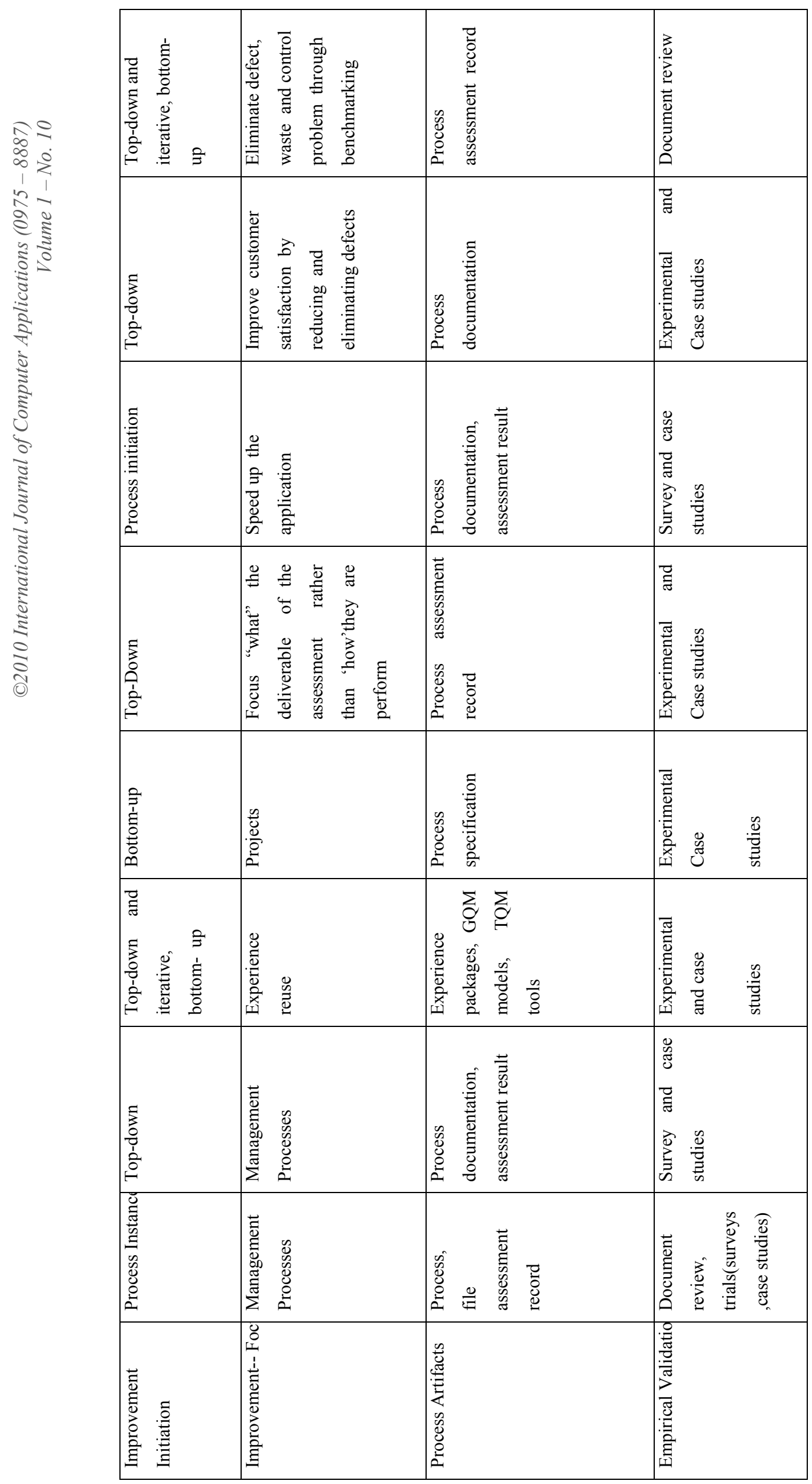

i 